\title{
KEANEKARAGAMAN JENIS TUMBUHAN OBAT-OBATAN DAN PEMANFAATANNYA BERDASARKAN PENGETAHUAN MASYARAKAT LOKAL DI KECAMATAN MALINAU UTARA KABUPATEN MALINAU KALIMANTAN TIMUR
}

\author{
P. S. Ajiningrum \\ Staf pengajar Prodi Biologi F MIPA Universitas PGRI Adi Buana Surabaya
}

\begin{abstract}
The objective of the study was to know local knowledge system of Dayak people in East Kalimantan. The data was collected using interview method to gather all information on plant diversity and it usage by the local society based on their own perception. The interview is using purposive sampling technique, conducted on the local society respondents whether male or female with a lifespan of 18 years or older. The number of respondents is $20 \%$ of the people in every sub district who took the Non Timber Forest Products (NTFPs) in the forest. The result of this research showed that many local people have a good knowledge about diversity surround them. Based on the results of interview, there were 31 plants species which were used as medication by the people. The factors relating to the cultural significance of plants would be discussed in detail in this article.
\end{abstract}

Keywords: Timber Forest Products (NTFPs), Index of Cultural Significance (ICS), local society, interview

\section{PENDAHULUAN \\ Latar Belakang}

Masyarakat Dayak di Kabupaten Malinau hidup di kawasan hutan tropis yang kaya akan keanekaragaman jenis flora dan fauna. Hampir seluruh kawasan di Kabupaten Malinau memiliki karakteristik topografi yang sebagian besar wilayahnya diklasifikasikan sebagai dataran rendah dan terdiri dari batuan aluvial yang subur. Pada umumnya, masyarakat Dayak bergantung pada sumber daya alam. Mereka mempraktekkan perladangan berpindah untuk menanam padi di dataran tinggi, berburu dan mengumpulkan hasil hutan.

Kehidupan masyarakat Dayak yang sangat tergantung pada hutan akhir-akhir ini semakin terancam oleh persaingan lahan dan konflik atas hutan untuk berbagai kepentingan pembangunan. Pemanfaatan lahan di bidang pertambangan, eksploitasi hutan dengan cara penebangan kayu dan perkebunan intensif menyebabkan degradasi sumber daya hutan dan lingkungan.

Dengan sarana dan prasarana yang terbatas, masyarakat Dayak telah mengembangkan pengetahuan, sistem kepercayaan, sistem sosial, menghimpun pengalaman dalam rentang waktu yang panjang. Mereka mengembangkan pengetahuan dengan mengolah alam sekitarnya untuk memenuhi kebutuhan sandang, pangan dan papan (Susiarti \& Setyowati 2005).

Sebelum pelayanan kesehatan modern dikenal, masyarakat Dayak memanfaatkan tumbuhan sebagai bahan obat-obatan dalam penanggulangan masalah kesehatan. Mereka juga mempunyai batasan aturan dalam memanfaatkan bahan hayati secara berkelanjutan yang dilandasi pengetahuan dan kearifan lokal yang diwariskan turun temurun sebagai tradisi.

Tumbuhan obat memiliki peran ekologi yang sangat penting. Tumbuhan obat yang beranekaragam jenis, habitus dan khasiatnya mempunyai peluang besar serta memberi kontribusi bagi pembangunan dan pengembangan hutan. Karakteristik berbagai tanaman obat yang menghasilkan produk berguna bagi masyarakat memberi peluang untuk dibangun dan dikembangkan bersama dalam hutan di daerah tertentu (Hamzari, 2008 dalam Hilala dkk, 2015).

Penelitian ini bertujuan untuk mengetahui status pengetahuan masyarakat di Kecamatan Malinau Utara dalam memanfaatkan potensi sumber daya tumbuhan obat. Hasil yang diharapkan adalah mengungkapkan jenis-jenis tumbuhan obat berguna yang berpotensi ekonomi dan berperan penting bagi masyarakat. Hal ini diharapkan dapat memberikan kontribusi terhadap konservasi pengetahuan masyarakat lokal yang mengeksplorasi sumber daya di sekitarnya.

\section{METODE PENELITIAN}

\section{Teknik pengumpulan data di lapangan}

Pengumpulan data etnobotani di lokasi studi melalui pendekatan emik. Pendekatan emik yaitu melakukan wawancara untuk mendapatkan jenis-jenis tumbuhan dan mengetahui pemanfaatannya kepada masyarakat lokal baik laki- 
laki atau perempuan yang mempunyai pekerjaan sebagai pengumpul, peramu, atau masyarakat yang sebagian sumber kehidupannya bergantung pada hasil hutan. Wawancara dilakukan secara semi structural dan open-ended kepada sejumlah informan dengan rentang umur 18 tahun keatas di lokasi penelitian maupun informan-informan lain yang dianggap relevan bagi kepentingan penelitian ini. Jumlah informan yaitu $20 \%$ dari jumlah masyarakat yang mengambil Hasil hutan non kayu (HHNK).

\section{HASIL PENELITIAN}

Bagi masyarakat lokal yang tinggal di sekitar hutan, tumbuhan tidak hanya berfungsi sebagai pemenuhan bahan pangan, tetapi juga untuk memenuhi kebutuhan kesehatan. Untuk keanekaragaman jenis tumbuhan yang dimanfaatkan sebagai bahan obat-obatan, hasil studi mencatat ada 31 spesies tumbuhan obat yang dikenali oleh masyarakat Dayak di Kecamatan Malinau Utara.

Tabel 1. Keanekaragaman jenis tumbuhan bahan obat tradisional masyarakat Dayak di Kecamatan Malinau Utara

\begin{tabular}{|c|c|c|c|}
\hline No & Nama Spesies & Nama Lokal & Kegunaan \\
\hline 1 & Acorus calamus & kariboro & Rimpangnya untuk bahan obat reumatik, demam pegal linu \\
\hline 2 & Allium tuberosum & bawang buda, kucai & Biji untuk bahan obat mencegah tumor, gangguan pencernaan \\
\hline 3 & Alpinia galanga & Lengkuas, lekoa & $\begin{array}{l}\text { Rhizoma untuk bahan obat penyakit kulit, pernapasan, kanker } \\
\text { mulut dan perut }\end{array}$ \\
\hline 4 & Blumea balsamifera & ingutap ba', sembung & $\begin{array}{l}\text { Daunnya sebagai bahan obat malaria, demam, kolera, batuk, } \\
\text { penawar racun ular reumatik dan sariawan }\end{array}$ \\
\hline 5 & Callicarpa longifolia & $\begin{array}{l}\text { kutao buda', ucung } \\
\text { ace }\end{array}$ & $\begin{array}{l}\text { Daun dan akar untuk bahan obat diare, dan setelah } \\
\text { melahirkan, demam, malaria }\end{array}$ \\
\hline 6 & Ceiba pentandra & $\begin{array}{l}\text { bua kafuk, kapuk } \\
\text { randu }\end{array}$ & Buahnya sebagai bahan obat \\
\hline 7 & Cinnamomum burmanii & kayu fesi’ & Kulit kayu dan daun untuk bahan obat sakit perut \\
\hline 8 & $\begin{array}{l}\text { Cinnamomum } \\
\text { javanicum }\end{array}$ & tabar & Kulit kayu dan daun untuk bahan obat \\
\hline 9 & Colocasia esculenta & ofa', talas & $\begin{array}{l}\text { Umbi dan daunnya sebagai bahan obat dan penangkal racun, } \\
\text { getahnya obat luka }\end{array}$ \\
\hline 10 & Cucurbita moschata & labu kuning & Biji untuk bahan obat \\
\hline 11 & Curcuma aeruginosa & temu hitam & Rhizoma untuk bahan obat asma dan batuk \\
\hline 12 & Curcuma domestica & lezu mit, kunyit & Rhizoma untuk bahan obat batuk, sakit perut \\
\hline 13 & Curcuma xanthorriza & Lezo, temulawak & Rhizoma untuk bahan obat sakit kembung, perut, batuk, asma \\
\hline 14 & Desmodium triflorum & Sisik betok (ind) & $\begin{array}{l}\text { Akar untuk obat nyeri lambung; daun untuk diare, disentri } \\
\text { dan bisul }\end{array}$ \\
\hline 15 & Eurycoma longifolia & pasak bumi & $\begin{array}{l}\text { Bahan obat malaria, tonikum, demam, pembersih darah, } \\
\text { disentri, sariawan, nafsu makan }\end{array}$ \\
\hline 16 & Eusideroxylon zwageri & Belien, kayu ulin & Buah untuk bahan obat, daun untuk sakit perut \\
\hline 17 & Kadsura scandens & Kilebur & $\begin{array}{l}\text { Semua bagian untuk obat batuk, radang tenggorokan, setelah } \\
\text { bersalin }\end{array}$ \\
\hline 18 & Kalanchoe pinnata & Ladak, sosor bebek & Daunnya sebagai bahan obat luka bakar \\
\hline 19 & Lansium domesticum & $\begin{array}{l}\text { bua lingat, langsit, } \\
\text { langsat }\end{array}$ & Biji dan kulit kayu untuk bahan obat \\
\hline 20 & Piper nigrum & $\begin{array}{l}\text { Sahang, sakang, lada } \\
\text { hitam }\end{array}$ & Buah untuk bahan obat hipertensi dan sesak napas \\
\hline 21 & Piper villipedunculum & Sakang hutan & Daun untuk bahan obat pada ternak babi \\
\hline 22 & Saccharum officinarum & Tebu & $\begin{array}{l}\text { Akar untuk obat disentri ; batang obat batuk dan tonikum, } \\
\text { tunasnya untuk obat sakit mata }\end{array}$ \\
\hline 23 & Saccharum spontaneum & Kaso, gelagah & Tunas untuk obat sakit mata \\
\hline 24 & Salacca affinis & salak & Buah dan pucuk daun untuk bahan obat sakit perut \\
\hline 25 & Salacca edulis & Salak & Buah dan pucuk daun untuk bahan obat sakit perut \\
\hline 26 & Salacca zalacca & sala“ & Buah dan pucuk daun untuk bahan obat sakit perut \\
\hline 27 & Sauropus androgynus & sangkuk manis, katuk & Daun sebagai bahan obat bisul, borok, pembersih darah kotor \\
\hline 28 & Uncaria ferrea & Kait besi & Daun untuk obat luka dan akar untuk radang usus \\
\hline 29 & Uncaria gambir & Gambir & $\begin{array}{l}\text { Daun untuk obat batuk, penyakit kuning, sakit perut, } \\
\text { amandel, dan mencegah ketombe }\end{array}$ \\
\hline 30 & Vitex pinnata & Felepo, laban & $\begin{array}{l}\text { Daunnya untuk obat demam, penambah nafsu makan, luka, } \\
\text { nyeri perut }\end{array}$ \\
\hline 31 & $\begin{array}{l}\text { Xanthophyllum } \\
\text { excelsum }\end{array}$ & Kayu telur (ind) & Kulit batang obat sakit perut ; biji obat sakit sariawan \\
\hline
\end{tabular}




\section{PEMBAHASAN}

Berdasarkan kategori pemanfaatan, tumbuhan obat banyak digunakan untuk mengobati sakit perut, untuk demam serta pegal linu. Pemanfaatan lain adalah untuk pengobatan penyakit kulit, penyakit infeksi dan sakit pernafasan, sakit gigi dan sariawan, sakit malaria dan lain sebagainya. Secara rinci, kategori penyakit yang dikenal masyarakat dan jumlah jenis tumbuhan yang digunakan sebagai ramuan pengobatan ditampilkan pada tabel 2 dibawah ini. Selanjutnya, bagian tumbuhan yang paling banyak digunakan yaitu berasal dari daun (17 spesies), buah (7 spesies), akar (5 spesies), rhizoma (5 spesies), biji (4 spesies) kulit kayu (4 spesies), dan juga kulit batang, tunas muda, umbi, rimpang dan bunga.

Tabel.. Penyakit dan jumlah jenis tumbuhan yang digunakan untuk pengobatan

\begin{tabular}{|l|l|c|}
\hline No & \multicolumn{1}{|c|}{ Kategori Pemanfaatan } & Jumlah Spesies \\
\hline 1 & $\begin{array}{l}\text { Sakit saluran pencernaan (diare, disentri, } \\
\text { infeksi lambung) }\end{array}$ & 16 \\
\hline 2 & $\begin{array}{l}\text { Sakit saluran pernapasan (batuk, asma, sesak } \\
\text { napas) }\end{array}$ & 4 \\
\hline 3 & Demam & 2 \\
\hline 4 & Sakit mata & 4 \\
\hline 5 & Obat luka & 3 \\
\hline 6 & Malaria & 2 \\
\hline 7 & Reumatik, pegel linu & 4 \\
\hline 8 & Perawatan gigi, sakit gigi dan sariawan & \\
\hline
\end{tabular}

Berdasarkan hasil penelitian ini, terdapat 31 spesies yang berhasil diketahui dari hasil wawancara dengan masyarakat lokal. Pengetahuan yang mereka miliki umumnya berasal dari orang tua mereka, tukar pikiran dengan anggota masyarakat lainnya dan hasil pengalaman sendiri. Pengetahuan tersebut bersifat turun-menurun yang disampaikan secara lisan dan umumnya hanya diturunkan kepada orang kepercayaan atau dengan melakukan pertukaran pengetahuan baik dengan anggotanya sendiri atau dengan anggota kelompok lain. Selain itu, mereka juga mengenal berbagai jenis tumbuhan berguna tidak hanya sebagai bahan obat-obatan, tetapi juga sebagai bahan pangan (buah-buahan liar).

Masyarakat lokal di Kecamatan Malinau Utara secara tradisional sangat bergantung pada sumber daya alam yang tersedia. Untuk mencukupi kebutuhannya, mereka berburu, meramu, berladang dan melakukan usaha tani lainnya. Akibat berbagai aktivitas tersebut, terdapat dampak perubahan keanekaragaman hayati, baik pada tingkat genetik, tingkat jenis, maupun tingkat ekosistem. Menurut Munawaroh (2006), aktifitas usaha tani yang dilakukan oleh masyarakat lokal dapat menyebabkan berkurangnya keanekaragaman jenis tumbuhan primer di hutan. Sebaliknya, pada tingkat genetik, sistem usaha tani tradisional dapat meningkatkan keanekaragaman genetik. Hal ini ditandai dengan terdapatnya keanekaragaman kultivar lokal berupa jenis tanaman budidaya. Keberadaan kultivar lokal ini bisa saja terjadi karena adanya persilangan secara alami diantara kultivar lokal yang ditanam secara campuran dalam suatu areal pertanian.

\section{KESIMPULAN DAN SARAN \\ Kesimpulan}

Dalam studi tentang keanekaragaman jenis HHNK bagi masyarakat lokal di Kecamatan Malinau Utara, pengetahuan botani sangat penting untuk diketahui. Pengetahuan tersebut bertujuan untuk memudahkan mereka mengenali jenis-jenis dan potensi tumbuhan agar dapat dimanfaatkan secara optimal. Pemanfaatan keanekaragaman jenis HHNK yang terdokumentasi dalam penelitian ini adalah 31 jenis tanaman diperuntukkan untuk obatobatan. Bagian tumbuhan yang paling banyak digunakan yaitu berasal dari daun (17 spesies), buah (7 spesies), akar (5 spesies), rhizoma (5 spesies), biji (4 spesies) kulit kayu (4 spesies), dan juga kulit batang, tunas muda, umbi, rimpang dan bunga.

\section{Saran}

Hasil penelitian ini diharapkan dapat memberikan wawasan bahwa pengetahuan lokal tentang pemanfaatan sumber daya HHNK sangat potensial untuk dikembangkan. Pengetahuan masyarakat lokal yang berkembang turun-temurun dapat membantu dalam usaha konservasi lingkungan.

\section{DAFTAR PUSTAKA}

Hamzari. 2008. Identifikasi Tanaman Obat-Obatan Yang Dimanfaatkan Oleh Masyarakat Sekitar Hutan Tabo-Tabo. Jurnal Hutan Dan Masyarakat Vol. III No. 2 Agustus 2008, 111-234.

Hilala P, J. Ahmad, dan M. S. Hamidun. Keanekaragaman Jenis Tumbuhan Obat 
Tradisonal Di Dataran Rendah Suaka Margasatwa Nantu Kabupaten Gorontalo.

Munawaroh. 2006. Keanekaragaman jenis tumbuhan berguna dan pemanfaatannya oleh masyarakat suku Anak Dalam, Jambi.
Prosiding Seminar Nasional Biodiversitas. Universitas Airlangga, Surabaya: 282-293. Susiarti, S. \& F. M. Setyowati. 2005. Bahan rempah tradisional dari masyarakat Dayak Kenyah di Kalimantan Timur. Biodiversitas 6(4): 289-291. 